\title{
Formulation and evaluation of erythropoietin-alginate microspheres at different amount of drug
}

\author{
Dewi Melani Hariyadi*, Esti Hendradi, Khoirotul Lailiyah \\ Department of Pharmaceutics, Faculty of Pharmacy \\ Universitas Airlangga, Surabaya, Indonesia
}

Submitted: 08-03-2018

Reviewed: 04-07-2018

Accepted: 02-11-2018

\begin{abstract}
This research formulate erythropoietin-alginate microspheres and to evaluate characteristics of erythropoietin-alginate microspheres at different amount of drug using aerosolization. Amount of erythropoietinare 10,000 IU (F1); 20,000 IU (F2); 60,000 IU (F3). The mixture of erythropoietinalginate was sprayed into $\mathrm{CaCl}_{2}$ and was stirred at $1000 \mathrm{rpm}$ for 30 minutes. Formulas resulted spherical shape of microspheres. The size of microspheres was $2.77 \mu \mathrm{m}$ for F1; $3.89 \mu \mathrm{m}$ for F2; and $4.42 \mu \mathrm{m}$ for F3. The results of swelling index showed that swelling index of microspheres increased by increasing the concentration of erythropoietin. The results were in accordance with the size of the microspheres that increased with increasing concentration of drug. The yields of microspheres obtained were respectively $91.92 \% ; 87.53 \% ; 86.50 \%$ for F1, F2 and F3. It can be concluded that the particle size of microspheres, swelling index increased by increasing concentration of erythropoietin. In contrast, yield of microspheres decreased by increasing drug concentration. In conclusion, formulas of microspheres were potential in terms of characteristics and may recommend for further in vivo study.
\end{abstract}

Keywords: erythropoietin, alginate microspheres, drug concentration, aerosolization

\footnotetext{
*Corresponding Author:

Dewi Melani Hariyadi

Faculty of Pharmacy, UniversitasAirlangga, Surabaya

J1. Dharmawangsa Dalam Surabaya

E-mail address: dewi-m-h@ff.unair.ac.id
} 


\section{INTRODUCTION}

Erythropoietin is a $30.4 \mathrm{kDa}$ glycoprotein hormone which is the main regulator of red blood cell production (Prenggono, 2015). Erythropoietin has a protective role against tissue ischaemia (Pachos, 2008). Erythropoietin, which is a protein, has several weaknesses, such as unstable in biological fluids because of easily digested by enzymes, cannot be fully absorbed from the digestive tract due to a high molecular weight resulting to low bioavailability, and has short half-life (Wang et al., 2013). Erythropoietin is stable at $\mathrm{pH} \mathrm{4-<9}$ and has the highest activity at $\mathrm{pH} \mathrm{7-8} \mathrm{(Chang} \mathrm{et} \mathrm{al.,} \mathrm{2013).}$ Erythropoietin is also stable at $-20^{\circ} \mathrm{C}$ or $-70^{\circ} \mathrm{C}$ (Chang et al., 2013). At pH 9 and $40{ }^{\circ} \mathrm{C}$, erythropoietin will undergo dimerization to form large molecules that can induce the body's immune response, which can harm patients (Chang et al., 2013). Some alternative is by formulatemicrospheressystem to release the drug in a sustained release manner (Chaudhary et al., 2010).

Microspheres are a drug delivery system in which the drug is diluted or dispersed homogeneously in the polymer matrix (Kumar et al., 2011). The advantage of a microsphere delivery system is that the drug's release properties in the body occur gradually, making it suitable for carrying the necessary drugs into the body with a fixed amount. In addition, the microspheres can also protect peptide/protein drugs from hydrolytic enzyme attacks (Takada, 2008).

The manufacture of erythropoietin microspheres by ionic gelation method and aerosolization technique requires polymers and crosslinking solutions. One of the most commonly used natural polymers is alginate.

Alginate is a polysaccharide which is a salt of alginic acid, comprising a monomer (1-4)- $\beta$-Dmanuronic acid (unit $\mathrm{M}$ ) and $\alpha$-L-guluronic acid (unit $\mathrm{G}$ ) that varies in quantity and distribution along its polymer chain (Pal et al., 2013). Na alginate is widely applied for biomedical purposes as a drug delivery system due to its biocompatibility, biodegradablity, low toxicity, relatively low cost, and lighter gelation by the addition of divalent cations such as $\mathrm{Ca}^{2+}$ (Hariyadi et al., 2014).

The frequently used crosslinking cations are divalent and trivalent cations (Ahirrao et al, 2014). The addition of monovalent metal ions to the alginate will form a soluble salt (Lee and Money, 2012). $\mathrm{Pb}, \mathrm{Cu}, \mathrm{Cd}$ cations are rarely used because they have some toxicity (Zhai, 2012). The use of Ba and $\mathrm{Sr}$ cations should be in low concentration as they are slightly toxic (Zhai, 2012). $\mathrm{Ca}^{2+}$ cations are often used because of their low toxicity and lack of high affinity for alginates (Zhai, 2012).

The ionic gelation method is based on the ability of the polyelectrolyte to be crosslinked in the presence of crosslinking ions forming a hydrogel. This method is prepared by dripping the drugpolymer solution into a cation polivalent solution. The cation diffuses into the droplets of a polymer solution, forming a three-dimensional crosslinked formation (Patil et al., 2012). The ionic gelation method is suitable for the active ingredients of proteins because of the simple and light process, which is greatly helpful for maintaining the bioactivity of the proteins (Koppolu et al., 2014). The advantage of the ionic gelation method is that all polyelectrolytes are diluted in the water so that the protein can be encapsulated without the use of organic solvents and the ionic gelation method does not use high temperatures so that protein integrity is maintained. In addition, this method is considered simple, fast, cost-effective, and has a small particle size diameter (Hariyadi et al., 2014).

Microspheres that have been formed will undergo the drying process. The drying process of microspheres in this research was the freeze drying technique, because it is able to maintain protein integrity during the drying process (Abdelwahed et al., 2006). The freeze drying process requires pressure during the freezing and drying processes, requiring a lyoprotectant (Abdelwahed et al., 2006). A lyoprotectant can stabilize the microsphere through the mechanism of hydrogen bond formation with polar groups on the surface of the microsphere at the end of the drying process in order to maintain the microsphere structure and replace the water's position on the microsphere surface (Abdelwahed et al., 2006). One of the usable lyoprotectants is maltodextrin, because it protects protein stability during the freezing and drying (Hariyadi et al., 2014)

Factors that may affect the characteristics of the resulting microsphere are the number of polymers, the number of crosslinkers, the amount of drug ingredients used, and the crosslinking time 
(Jin et al., 2009). The higher the concentration of the drug, the higher the microspheres size that is obtained (Wang et al., 2013). In a study conducted by Balasubramaniam et al. (2007) on the effect of drug concentration on microsphere size using the emulsification technique, it was found that the greater the concentration of drug used, the greater the microsphere size that is obtained. This was because the higher the concentration of the drug, the greater the droplet size produced, resulting in the larger size of the formed microsphere (Balasubramaniam et al., 2007). The microspheres size range generated from the study was 47-50 $\mu \mathrm{m}$ (Balasubramaniam et al., 2007). In addition, increasing the concentrations of medicinal ingredients may also increase the efficiency of encapsulation (Balasubramaniam et al., 2007). The differences of the research conducted by Balasubramaniam et al. (2007) with this research is on aerosolization technique used in method of produced microspheres, therefore it is expected that the microsphere particle size formed is $<5 \mu \mathrm{m}$. The determination of target size of microspheres of $<5 \mu \mathrm{m}$ is adjusted to the particle size requirement for suspensions (Patel, 2010).

This study was conducted to determine the effect of erythropoietin amount $(10,000,20,000$, $60,000 \mathrm{IU})$ on erythropoietin-alginate microspheres characteristics using ionotropic gelation method and aerosolization technique.

\section{MATERIALS AND METHODS \\ Materials}

Pharmaceutical grade Erythropoietin (Daewoong Inc.), Sodium alginate (Sigma-Aldrich Inc.), $\mathrm{CaCl}_{2} \cdot 2 \mathrm{H}_{2} \mathrm{O}$ (Solvay Chemicals International), demineralized water, pro-analysis $\mathrm{Na}_{2} \mathrm{HPO}_{4}(\mathrm{Merck})$, $\mathrm{KH}_{2} \mathrm{PO}_{4}$ (Merck), $\mathrm{NaCl}$ (Merck), $\mathrm{NaOH}$ (Merck), and pharmaceutical grade Maltodextrin (PT Bratachem).

\section{Research Method \\ Microspheres formula}

Sodium alginate (2 gram) were dissolved into $100 \mathrm{~mL}$ of demineralized water. Erythropoietin was dispersed into $100 \mathrm{~mL}$ of alginate solution based on drug concentration. After that, $\mathrm{CaCl}_{2}$ solution $_{2} 1 \mathrm{M}$ was made in $200 \mathrm{ml}$ aqua demineralized by stirring homogeneously. The formed erythropoietin-alginate solution was then sprayed into $\mathrm{CaCl}_{2}$ solution using aerosol spray with a 35 $\mu$ mhole size and a constant pressure of 40 psi while being continuously stirred using a magnetic stirrer at $1000 \mathrm{rpm}$ for 30 minutes. The microspheres suspension that had been formed was centrifuged at $4000 \mathrm{rpm}$ for 10 minutes, then washed with demineralized water 3 times to separate the microspheres from the $\mathrm{CaCl}_{2}$ solution. The washed microspheres were collected and dried using the freeze drying technique at $-26^{\circ} \mathrm{C}$ for 38 hours.

Table I. Erythropoietin-alginate microspheres formulas

\begin{tabular}{|c|c|c|c|c|}
\hline Materials & Function & F1 & F2 & F3 \\
\hline Erythropoietin & Active agent & $10.000 \mathrm{IU}$ & $20.000 \mathrm{IU}$ & $60.000 \mathrm{IU}$ \\
\hline Na Alginate & Polymer & $2 \%$ (in $100 \mathrm{ml}$ ) & $2 \%$ (in $100 \mathrm{ml}$ ) & $2 \%($ in $100 \mathrm{ml})$ \\
\hline $\mathrm{CaCl}_{2}$ & Crosslinker & $\begin{array}{c}1 \mathrm{M}(\text { in } 200 \mathrm{ml}) \\
5 \%\end{array}$ & $\begin{array}{c}1 \mathrm{M}(\text { in } 200 \mathrm{ml}) \\
5 \%\end{array}$ & $\begin{array}{c}1 \mathrm{M}(\text { in } 200 \mathrm{ml}) \\
5 \%\end{array}$ \\
\hline Maltodextrin & Lyoprotectant & $\begin{array}{l}\text { (from wet } \\
\text { microspheres } \\
\text { weight) }\end{array}$ & $\begin{array}{c}\text { (from wet } \\
\text { microspheres } \\
\text { weight) }\end{array}$ & $\begin{array}{l}\text { (from wet } \\
\text { microspheres } \\
\text { weight) }\end{array}$ \\
\hline
\end{tabular}




\section{Evaluation of erythropoetin-alginate microspheres \\ Particle size distribution}

The evaluation of erythropoietin-alginate microsphere size distribution was performed using 400x optical microscope magnification. The diameter of erythropoietin-alginate microspheres was observed with a 400x magnification of 300 particles. Then, the mean diameter was determined and the microsphere size distribution curve was made. The average diameter was calculated using the formula:

$$
\operatorname{dvs}=\frac{n d^{\mathrm{s}}}{n d^{2}}
$$

\section{Microspheres shape and surface morphology}

The morphological evaluation of erythropoietin-alginate microspheres and surface forms was performed using a Scanning Electron Microscope (SEM). This evaluation was performed by placing a sample on the handle of the preparation with an adhesive material containing metal grains, such as the metal Pt. The gold in the Chamber was evaporated so that the gold steam coated the entire surface of the microparticles. The surface of the gold-coated microparticles was observed using SEM to observe the morphology of the shape and surface of the microspheres.

\section{Moisture content determination}

The moisture content determination on erythropoietin alginate microspheres can be determined using the moisture balance. This evaluation can be performed by weighing 0.5 grams of microspheres and inserting them into the moisture balance. The tool would work for 10 minutes. The moisture content (MC) was calculated by the equation: $\mathrm{MC}=\frac{\text { Initial weight-Final weight }}{\text { Final weight }} \times 100 \%$

\section{Determination of Swelling Index (SI)}

The determination of swelling index was performed by weighing $50 \mathrm{mg}$ microspheres and then adding $5 \mathrm{ml}$ PBS pH 7.4 in a vial. The swelling index determination was performed at 24 and 30 hours. After the observation time had been reached, the wet microspheres were filtered using filter paper. After no PBS was dripped from the filter paper, the wet microspheres were transferred to a dry filter pad and then the microspheres were flipped continuously to remove the adsorbed water on the microsphere surface until the filter paper became not too wet. Afterwards, the wet microspheres were stirred at $37^{\circ} \mathrm{C}$ for 2 hours or until the microspheres weight became constant. The microspheres was weighed as the swelling weight. The swelling index (SI) value was calculated using the formula:

$$
\mathrm{SI}=\frac{\text { Swelling weight-Dryweight }}{\text { Dryweight }}
$$

The swelling index observation was also performed based on the microsphere ssize. A little amount of microsphere were taken to be observed for microspheres size during swelling using an optical microscope. The swelling index (SI) value was calculated using the formula:

Swelling microsphere size-Dry microsphere size

Dry microsphere size

\section{Yield determination}

The yield value was determined by the ratio of the total weight of the dry microspheres obtained to the amount of weight of erythropoietin, sodium alginate, and maltodextrin. The yield value can be calculated by the formula: 


$$
\text { Yield }(\%)=\frac{\text { total microspheres weight }(\mathrm{mg})}{\text { alginate }+ \text { erythropoietin }+ \text { maltodextrin weight }(\mathrm{mg})} \times 100 \%
$$

The data from each examination were compared with each of the formulas. The data analysis was performed using SPSS 23 statistical program using the One Way ANOVA method.

\section{RESULTS AND DISCUSSION}

The mean diameter for blank microspheres was $2.31 \mu \mathrm{m}$ and the mean diameters of $\mathrm{F} 1$ microspheres, F2, F3 using 400 times magnification were $2.77 \pm 0.08 \mu \mathrm{m} ; 3.89 \pm 0.12 \mu \mathrm{m}$; and $4.42 \pm$ $0.06 \mu$ mrespectively (Figure 1). These results indicated that blank microspheres were smaller than the three formulas microspheres with erythropoietin. The observation also showed an increase in the size of the microsphere as the levels concentration of erythropoietin from F1 to F3 increased with the values of $10,000,20,000$, and $60,000 \mathrm{IU}$. The average microspheres diameter result met the specification of $<5 \mu \mathrm{m}$, where the size is considered good for a parenteral suspension (Patel, 2010).

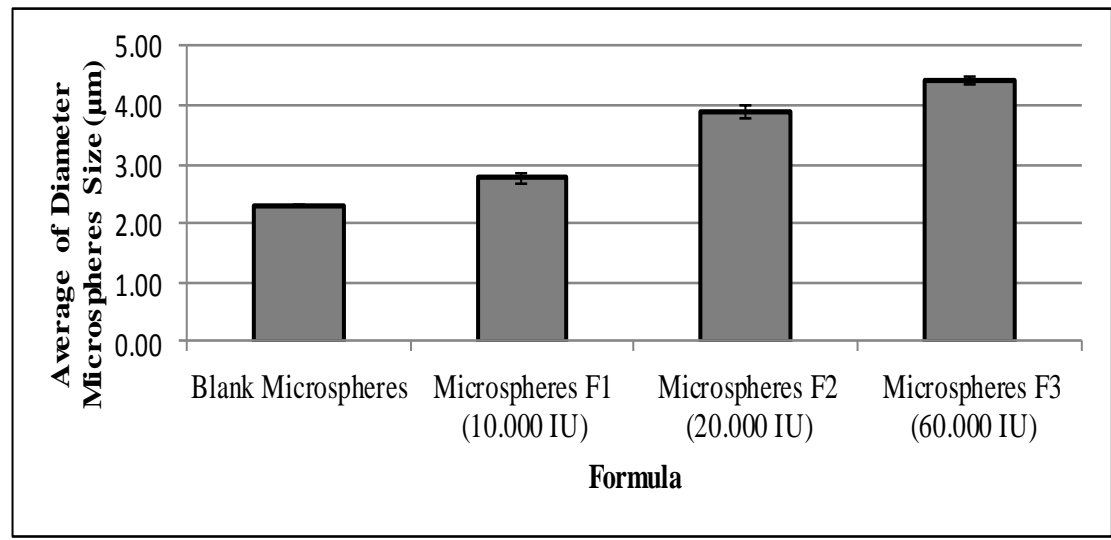

Figure 1.Histogram of diameters of microspheres sizes of blank microspheres and microspheres of F1, F2 and F3

The microspheres size increased by addition of erythropoietin levels was due to two factors. First, the higher the amount of erythropoietin, the more erythropoietin can filled the remaining empty egg-box structures. Second, there was a repulsive force between erythropoietin and alginate. Alginate as a bioelectrolyte can caused repulsive force with erythropoietin. The repulsive force occurred between the $\mathrm{COO}^{-}$group of alginate with the $\mathrm{COO}$ - group of erythropoietin. The larger the erythropoietin, the greater the repulsive force that occurs with alginate. The existence of such repulsive forces may increase the viscosity, resulting in increased microsphere size (Chaudhari et al., 2015).

In the analysis of the effect of erythropoietin levels on microspheres, sig values of $0.000<0.05$ for $\mathrm{F} 1: \mathrm{F} 2 ; 0.000<0.05$ for $\mathrm{F} 1: \mathrm{F} 3$; and $0.001<0.05$ for $\mathrm{F} 2: \mathrm{F} 3$ were obtained. The three comparisons of the formula showed sig values of $<0.05$, so we can say there is a significant difference in microsphere size between F1, F2, and F3.

The morphological observations of the shape and surface of the microspheres using the Scanning Electron Microscope (SEM) of the F1, F2, F3resulted in spherical and smooth shapes (Figure 2). These results can be obtained due to the addition of maltodextrin as a lyoprotectant which made the form of the microsphere to be spherical with a smooth and flat surface. The maltodextrin would filled the cavity on the surface of the microsphere and form the hydrogen bond with the polar group on the microsphere surface during the freeze drying process (Abdelwahed et al., 2006). 


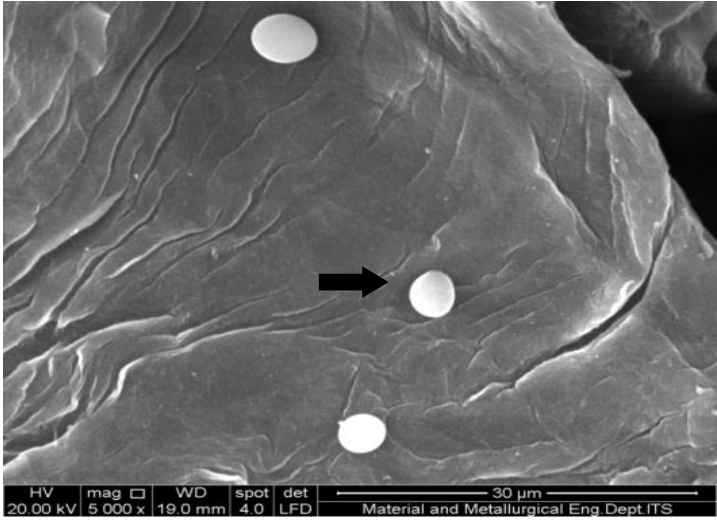

(A)

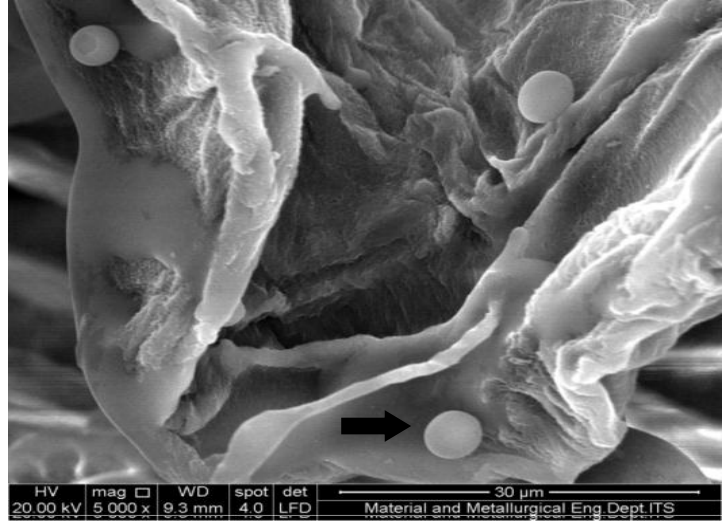

(B)

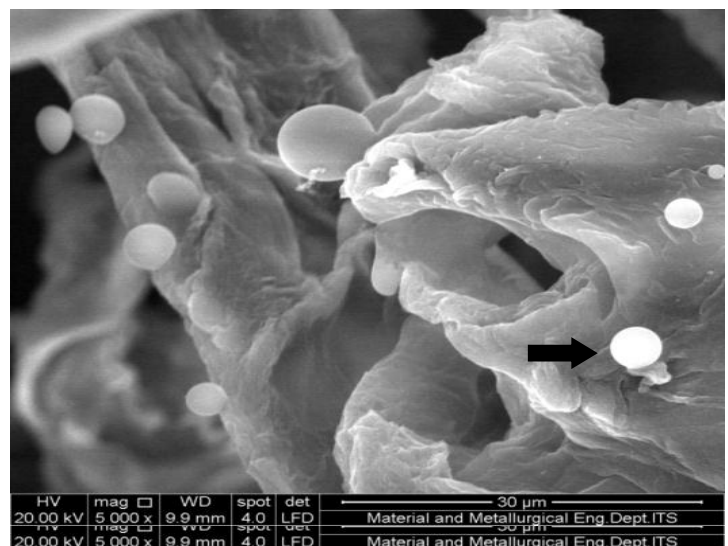

(C)

Figure 2. The shape and surface morphology of the erythropoietin microspheres (A) F1, (B) F2, (C) F3 observed using the ScanningElectron Microscopy at 5000x magnification

The result of MC determination showed that the average of water content in the three formulas were $5.85 \pm 0.10 \%$; $5.08 \pm 0.13 \%$; and $8.08 \pm 0.21 \%$ as seen in Table I. The MC of three formulas corresponded to specifications of MC of $<10 \%$. The high moisture content can decreased the stability of the active ingredients in the microspheres due to the formation of particle agglomeration (Shan $e t$ al., 2016).

Table II. Moisture content of microspheres formula

\begin{tabular}{ccc}
\hline Microspheres Formula & MC (\%) \pm SD & CV (\%) \\
\hline F1 & $5.85 \pm 0.10$ & 1.71 \\
F2 & $5.08 \pm 0.13$ & 2.56 \\
F3 & $8.08 \pm 0.21$ & 2.60 \\
\hline
\end{tabular}

From the determination of swelling index, the average swelling index at 24 hours based on the weights of microspheres in formula F1, F2 and F3 were $1.300 \pm 0.071 ; 1.463 \pm 0.046 ; 1.749 \pm 0.044$, while during the observation at 30 hours, the average swelling index based on the weight of the microsphere in the formula F1, F2, and F3 were $1.867 \pm 0.056 ; 2.272 \pm 0.154 ; 2.475 \pm 0.189$. The average swelling indices at 24 hours based on microspheres sizes in the formula F1, F2, and F3 were $1.13 \pm 0.10 ; 1.37 \pm 0.05 ; 1.67 \pm 0.04$, respectively. Meanwhile, during the observation at 30 hours, the 
average swelling indices based on the microspheres size in formulas F1, F2, and F3 were $1.85 \pm 0.04$; $2.07 \pm 0.12 ; 2.28 \pm 0.15$.

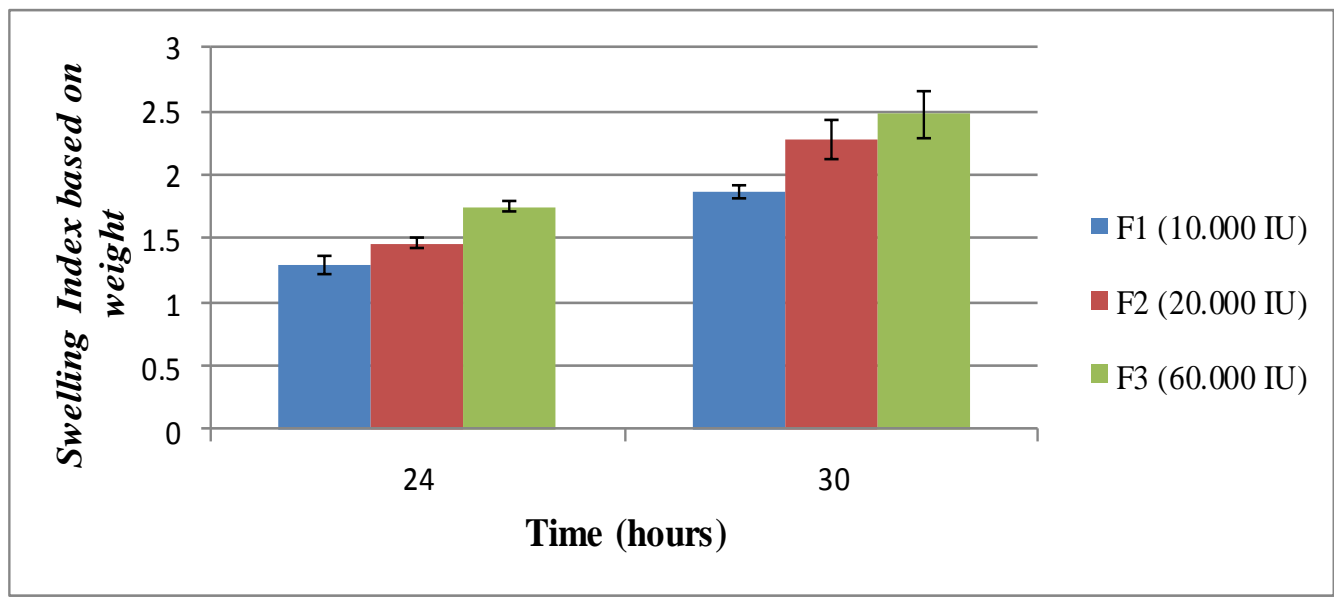

Figure 3. The swelling index histogram based on weight of microspheres F1, F2, F3

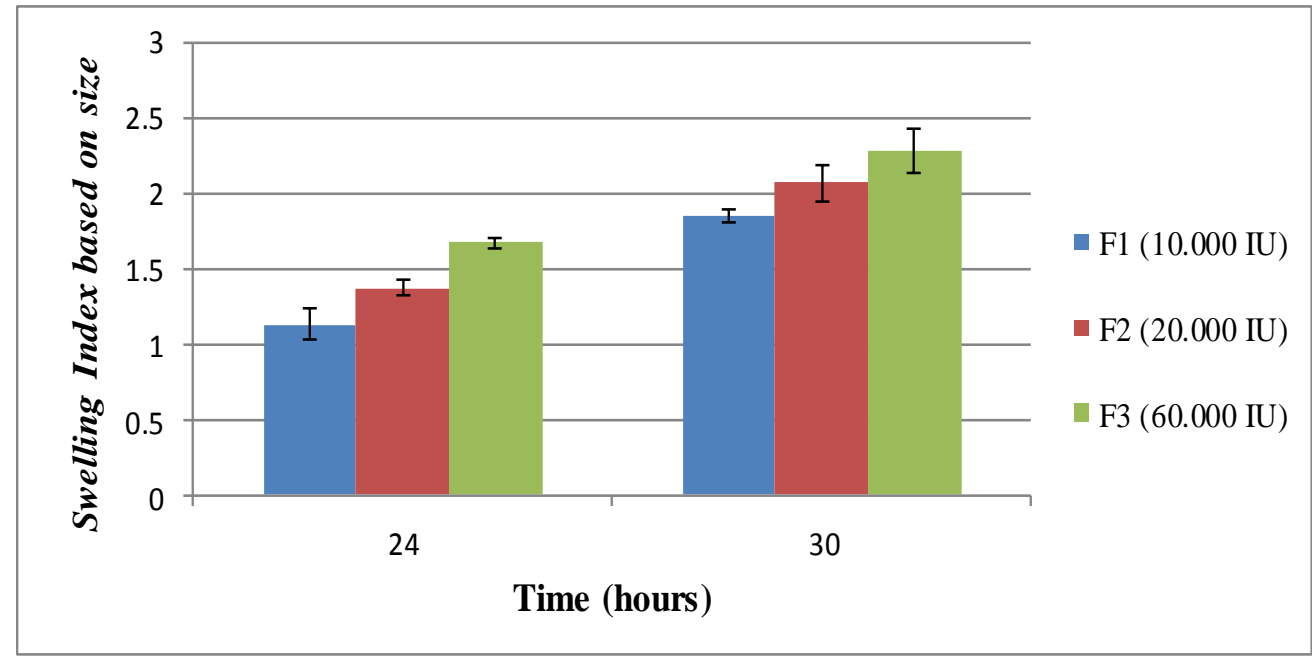

Figure 4. The swelling index histogram based on the size of microspheres of F1, F2, F3

The average swelling indices based on microsphere weight at 24 hours and 30 hours yielded gave greater result than swelling indices based on microspheres sizes. However, if it was tested statistically using the independent t-test, the difference of swelling indices between microsphere weight and microsphere size was not significant due to the 2-tailed sig value $>0.05$. The increase of swelling index values at 24 to 30 hours based on the weight and size of microspheres can be said to differ significantly because the independent t-test results showed that the 2-tailed sig value $<0.05$.

When we looked at the average swelling index results, both based on microsphere weight and microsphere size, it seems that both yielded the same resulted that the swelling index value increased with the increased of the ingredients added in the formula. This corresponded to the average yield of microspheres in which microsphere sizes increased with the ingredients added in the formula. The swelling index results based on microsphere weight and microspheres size were also in accordance 
with the theory, where the higher the observation time, the higher the swelling index value was obtained (Navneet et al., 2011).

The swelling index evaluation was used to ensure the polymer can expand, then it can released drug. Alginate, in releasing drug substances, had diffusion, swelling, and erosion mechanisms (Fernanda et al., 2014). The results of the evaluation have been found to be in accordance with the theory in which alginate can expand, as evidenced by the addition of weight and size of microspheres after being put aside for 24 and 30 hours.

From the result of yield determination, the average yields obtained in formula F1, F2, and F3 were $91.92 \pm 3.33 \% ; 87.53 \pm 6.01 \% ; 86.50 \pm 4.59 \%$. From these results, it is known that the value of the yield fallen along with the increase of the ingredient content of the drug added in the formula. This was because microspheres have entrapment capacities in entrapping drug ingredients (Rastogi et al., 2007). The increasing yield values indicated that erythropoietin with a level of $>10,000 \mathrm{IU}$ is not entirely entrapped in the microspheres and was dissolved when washed with water since erythropoietin was also soluble in water. The results of statistical analysis showed that the effect of erythropoietin content on yield was mas determined by sig values of $0.534>0.05$ for F1: F2; $0.403>0.05$ for F2: F3; and $0.963>0.05$ for F2: F3. The three comparisons of the formula showed sig values of $<0.05$, so we can say there is a significant difference in microspheres size between F1, F2, and F3.

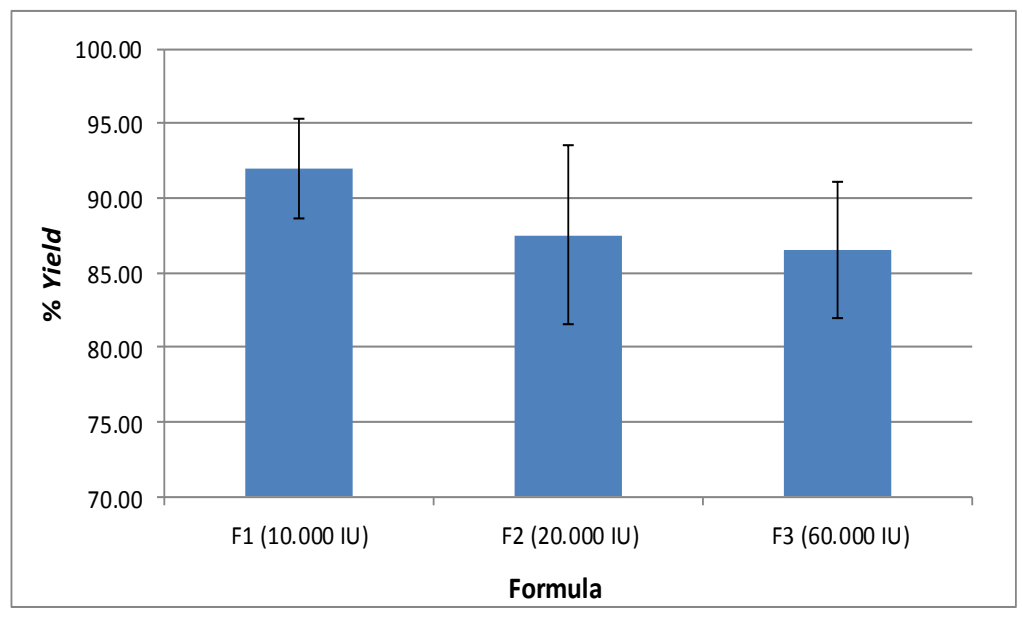

Figure 5. Histogram of \% yield of microspheres of F1, F2, F3

\section{CONCLUSION}

The formulation of erythropoietin-alginate microspheres by the ionic gelation method and aerosolization technique with different erythropoietin amount (10,000, 20,000, 60,000 IU) resulted in microspheres which were spherical and smooth. Increasing levels of erythropoietin increased the size of the microspheres and swelling index significantly, but did not have a significant effect on yield.

\section{ACKNOWLEDGMENTS}

The author would like to thank the Faculty of Pharmacy, Universitas Airlangga for all supports in this research.

\section{REFERENCES}

Abdelwahed, W., Degobert, G., Stainmesse, S., and Fessi, H., 2006. Freeze-drying of nanoparticles: Formulation, process and storage considerations, Advanced Drug Delivery Reviews, 58: 16931696. 
Ahirrao, S. P., Gide, P. S., Shrivastav, B., and Sharma, P., 2014. Ionotropic Gelation : A promising cross linking technique for hydrogels, Journal of Pharmaceutic and Nanotechnology, 2(1): 1-6.

Balasubramaniam, Vinay U. Rao, M. Vasudha, Jeevan Babu and P.S. Rajinikanth., 2007. Sodium alginate microspheres of metformin $\mathrm{HCl}$ : formulation and in vitro evaluation. Current Drug Delivery, 4(3): 249-256.

Koppolu, B.P., Sean G. Smith, Sruthi Ravindranathan, Srinivas Jayanthi, Thallapuranam K.S. Kumar, David A. Zaharoff, 2014. Controlling chitosan-based encapsulation for protein and vaccine delivery, Biomaterials, 35(14): 4382-4389.

Chang, S.H. , Kim, H.J., and Kim, C. W.,2013. Analysis of the structure and stability of erythropoietin by $\mathrm{pH}$ and temperature changes using various LC/MS. Bull, Korean Chemical Society, 34(9): 2663-2670.

Chaudhari, S., R. Kar, J. and S. Singhal, R., 2015. Immobilization of proteins in alginate: functional properties and applications, Current Organic Chemistry, 19(17): 1732-1754.

Chaudhary, K., Haddadin, S., Nistala, R. and Papageorgio, C., 2010. Intraperitoneal Drug Therapy: An Advantage, Current Clinical Pharmacology, 5(2): 82-88.

Fernanda M. Carbinatto, Ana Dórisde, Castro Raul C., Evangelista Beatriz S.F.Cury, 2014. Insights into the swelling process and drug release mechanisms from cross-linked pectin/high amylose starch matrices, Asian Journal of Pharmaceutical Sciences, 9(1) : 27-34.

Hariyadi D.M., HendradiEsti, Purwanti Tutiek, Fadil F.D.G.P., Ramdani, C.N., 2014. Effect of crosslinking agent and polymer on the characteristic of ovalbumin loaded alginate microspheres, International Journal Of Pharmacy And Pharmaceutical Sciences, 6(4): 1-6.

Inanlou, F., Pejvak, K., Naser, M., Soheila, M.B., Hossein, Z., Chang, Y.F., Bazrafshan, M.R., and Saraei, F., 2015. Preparation of microspheres containing leptospiral antigen using biodegradable alginate polymers, Veterinarski Arhiv 85(4): 395-406.

Jin, M., Zheng, Y., Hu, Q., 2009. Preparation and Characterization of Bovine Serum Albumin Alginate/Chitosan Microspheres for Oral Administration, Asian Journal of Pharmaceutical Sciences: 215-221.

Kumar, B.T., Chandiran, I.S., Bhavya, B, and Sindhuri, M., 2011. Microparticulate Drug Delivery System : a Review, Indian Journal of Pharmaceutical Science and Research, 1: 19-31

Pal, K., Allan T.Paulson, Dérick Rousseau, 2013. 14 - Biopolymers in Controlled-Release Delivery Systems in Handbook of Biopolymers and Biodegradable Plastics, 329-363.

Lee, K. and Mooney, D., 2012. Alginate: Properties and biomedical applications, Progress in Polymer Science, 37(1): 106-126.

Navneet, G., Akanksha, G. and Neetesh, J., 2011. Formulation design and in-vitro evaluation of metformin microspheres using ionotropic gelation technique, Journal of Pharmacy Research, 4(7): 2103-2106.

Paschos, N., Lykissas, M.G., Beris, A.E., 2008. The Role of Erythropoietin as an Inhibitor of Tissue Ischemia, International Journal of Biological Sciences :161-168.

Patel, R., 2010, Parenteral Suspension: An Overview, International Journal of Current Pharmaceutical Research, 2(3): 1-10.

Patil, P., Chavanke, D., Wagh, M., 2012. A Review on Ionotropic Gelation Method: Novel Approach for Controlled Gastroretentive Gelispheres, International Journal of Pharmacy and Pharmaceutical Sciences, 4(4): 27-32.

Prenggono, M.D., 2015. Eritropoetindan penggunaan eritropoetin pada pasien kanker dengan anemia, CDK-224, 42(1): 20-26.

Rastogi, R., Y. Sultana, M., Aqil, S. Kumar,K.,Chuttani, A.K.Mishar, 2007. Alginate microspheres of isoniazid for oral sustained drug delivery, International Journal of Pharmaceutics: 334 (1-2): 71-77.

Shan, L., Tao, E. X., Meng, Q. H., Hou, W. X., Liu, K., Shang, H. C., Tang, J. B., and Zhang, W. F., 2016. Formulation, optimization, and pharmacodynamic evaluation of 
chitosan/phospholipid/ $\beta$-cyclodextrin microspheres, Drug, Design, Development and Therapy, $10: 417-429$.

Takada, K., 2008. Microfabrication-derived DDS: From batch to individual production,Drug Discoveries and Therapeutics, 2(3):140-155.

Yang, J., Xie, Y. and He, W. 2011. Research progress on chemical modification of alginate: A review. Carbohydrate Polymers, 84(1): 33-39.

Ying Wang, Xiaoping Yang, Wentao Liu, Feng Zhang, Qing Cai, Xuliang Deng, 2013. Controlled release behaviour of protein-loaded microparticles prepared via coaxial or emulsion electrospray, J Microencapsul, 30(5): 490-497.

Wang, L., Liu, Y., Zhang, W., Chen, X., Yang, T. and Ma, G., 2013. Microspheres and Microcapsules for Protein Delivery: Strategies of Drug Activity Retention, Current Pharmaceutical Design, 19(35): 6340-6352.

Zhai, P., 2012. Alginate microspheres for protein delivery in tissue engineering, A Thesis Division of Biomedical Engineering University of Saskatchewan: 1-72. 